\title{
THE RELATIONSHIP BETWEEN DENSITY AND TENSILE STRENGTH IN SNOW
}

\author{
By R. A. Sommerfeld \\ (Rocky Mountain Forest and Range Experiment Station, * Forest Service, U.S. Department \\ of Agriculture, Fort Collins, Colorado 8052 I, U.S.A.)
}

\begin{abstract}
Weakest link" theories predict that the brittle fracture of snow is inherently a statistical problem. The probability of failure of snow in centrifugal tensile tests is shown to be a function of $\sigma / \sigma_{\mathrm{m}}$ where $\sigma$ is the applied stress and $\sigma_{\mathrm{m}}$ is a characteristic strength (a maximum strength) which is a function of density $\rho$ alone. Similar probabilities of failure are obtained for measurements at Alta, Utah, and Berthoud Pass, Colorado where the characteristic strength is obtained from the relationship

$$
\log \sigma_{\mathrm{m}}=-4 \cdot 3+3 \log \rho .
$$

Resumé. La relation entre la densité et la résistance en tension de la neige. La théorie du "plus faible maillon" prévoit que la cassure de la neige est en soi un problème statistique. La probabilité de la rupture de la neige dans un essai de tension à la centrifugeuse est, a-t-on montré, une fonction du rapport $\sigma / \sigma_{\mathrm{m}}$ où $\sigma$ est l'effort appliqué et $\sigma_{\mathrm{m}}$ une résistance caractéristique (une résistance maximum) qui ne dépend que de la seule densité $\rho$. Des probabilités analogues de rupture sont obtenues par des mesures à Alta (Utah) et au Berthoud Pass (Colorado) où les résistances caractéristiques s'obtiennent par la relation
\end{abstract}

$$
\log \sigma_{\mathrm{m}}=-4 \cdot 3+3 \log \rho .
$$

Zusammenfassung. Der Zusammenhang zwischen Dichte und Zugfestigkeit in Schnee. Aus der Theorie vom "schwächsten Glied" geht hervor, dass das spröde Auseinanderbrechen von Schnee im wesentlichen ein statistisches Problem ist. Die Wahrscheinlichkeit des Bruches von Schnee ergibt sich aus zentrifugalen Dehnungsuntersuchungen als Funktion von $\sigma / \sigma_{\mathrm{m}}$, wobei $\sigma$ die angelegte Spannung und $\sigma_{\mathrm{m}}$ eine charakteristische Festigkeitsgrösse (eine Maximalkraft) ist, welche eine Funktion der Dichte $\rho$ allein ist. Ähnliche Bruchwahrscheinlichkeiten werden für Messungen bei Alta, Utah, und am Berthoud-Pass, Colorado, erhalten, wobei sich die charakteristische Festigkeit aus der Beziehung

ergibt.

$$
\log \sigma_{\mathrm{m}}=-4 \cdot 3+3 \log \rho
$$

ONE of the major impediments to the development of a failure criterion for low-density snow has been the very large scatter of the various strength measurements. (Bader and others, I939; Bucher, I948; Butkovich, I956; Ramseier, I963; Roch, I966; Keeler and Weeks, I967; Keeler, 1969; Martinelli, I97I). In most of the strength measurements and in the release of dry snow avalanches, the failure mechanism is brittle fracture. Brittle fracture is characterized by large scatter in strength measurements because stress concentrations near flaws in brittle materials are not relieved and the strength of any particular sample is determined not by its bulk properties but by the weakest flaw which is included in the sample (Griffith, 1920). Thus the large scatter in strength is an inherent property of snow and the development of a failure criterion is a statistical problem.

It has been shown that for brittle materials the probability of failure $R$ is a function of the ratio of the applied stress $\sigma$ to some characteristic stress $\sigma_{\mathrm{m}}$;

$$
R=R\left(\sigma / \sigma_{\mathrm{m}}\right)
$$

(Weibull, r939; Frenkel and Kontorova, I943). Also it seems reasonable to assume that $\sigma_{\mathrm{m}}$ is a function of the sample density $\rho$. The above hypotheses can be tested with available centrifugal tensile-strength data (Butkovich, I956; Keeler and Weeks, I967; Keeler, I969; Martinelli, I97I).

Figures I, 2, 3 and 4 are log-log plots of tensile strength versus density. It is apparent in Figures 1,2 and 4 that an envelope of maximum strength exists. The data shown in Figure 3

* Central headquarters maintained in cooperation with Colorado State University, Fort Collins, Colorado. 


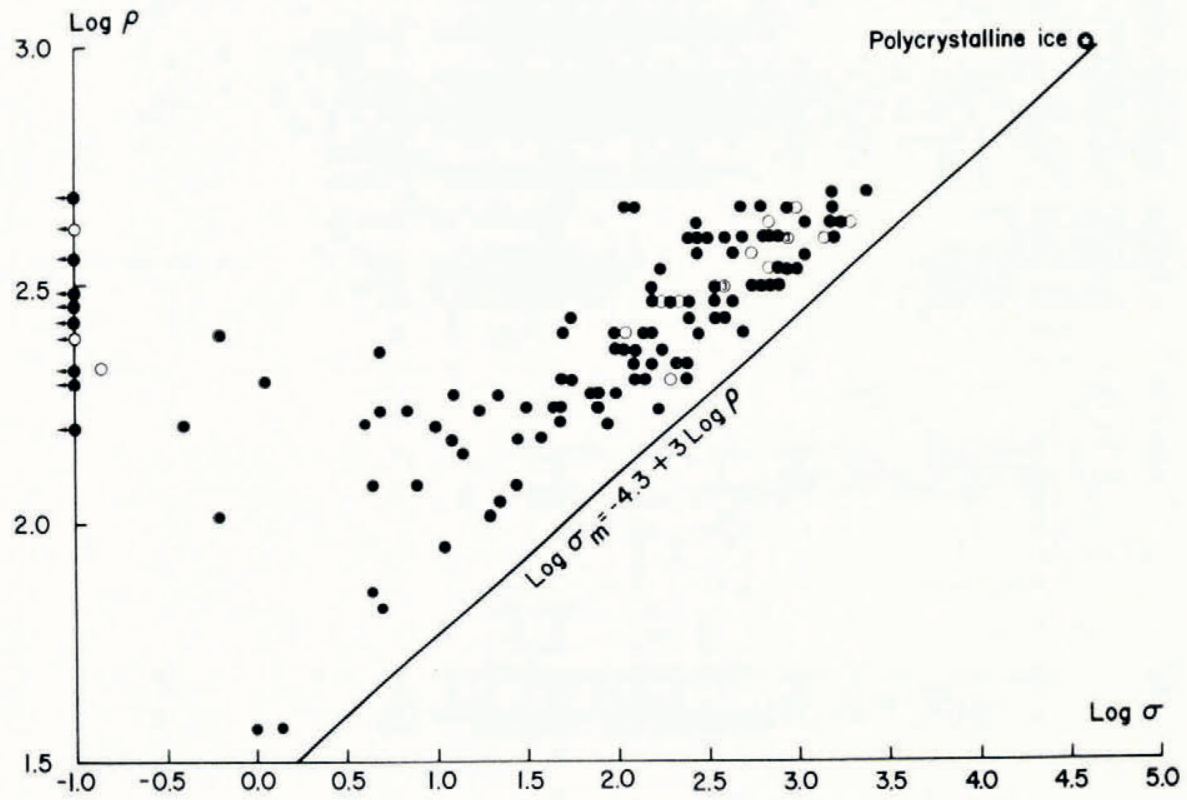

Fig. I. Logarithm of tensile strength $(\log \sigma)$ versus logarithm of density $(\log \rho)$ using data from Martinelli $(1971)$. data point, $\bigcirc$ two data points. A circle with a number in it indicates that number of data points.

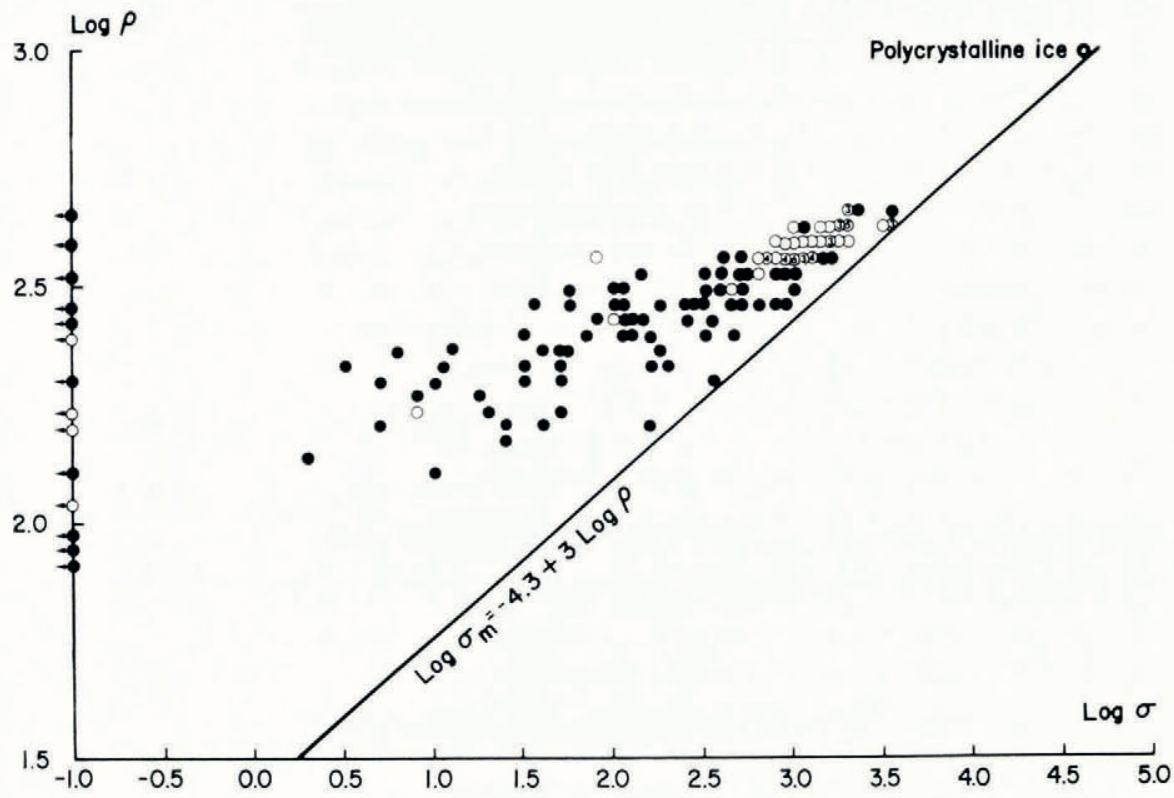

Fig. 2. Similar plot to Figure I using data from Keeler (1969). 
do not have a wide enough spread in density to clearly show an envelope. The envelope drawn in the figures fits the equation

$$
\log \sigma_{\mathrm{m}}=-4 \cdot 3+3 \log \rho .
$$

It agrees with the measurements of Martinelli (197I), and Keeler (1969) and is not contradicted by those of Butkovitch (1956). However, the data of Keeler and Weeks (1967) require an envelope of steeper slope. It is interesting to note that reasonable envelopes drawn to the data predict the highest available measurements of the tensile strength of polycrystalline ice (Butkovich, I959). Martinelli's (I97I) and Keeler's (1969) measurements were on fairly young snow, while those of Keeler and Weeks (1967) included old, highly metamorphosed snow which may have experienced some melt-freeze cycles. Thus there is an indication that the maximum strength is a weak function of metamorphic grade or snow type.

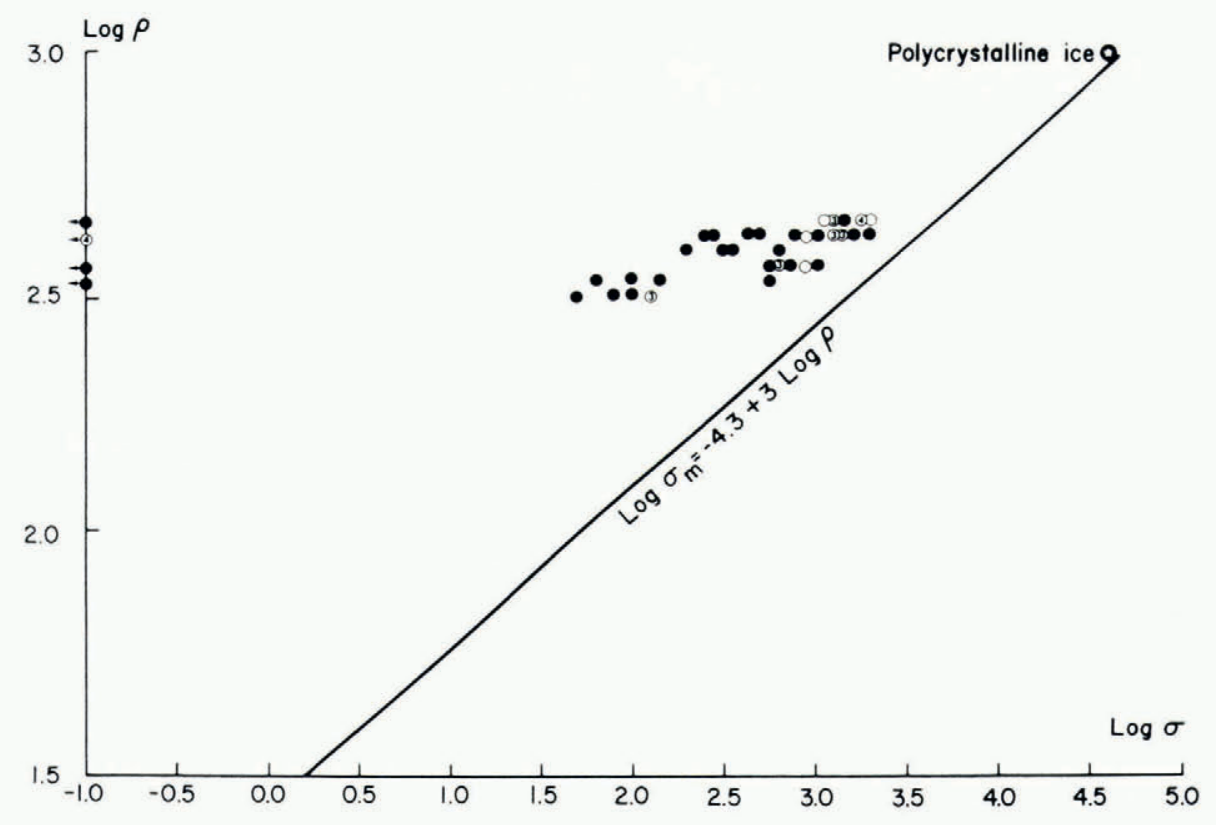

Fig. 3. Similar plot to Figure I using data from Butkovich (1956).

The probabilities of failure (cumulative frequencies) as functions of $\sigma / \sigma_{\mathrm{m}}$ were calculated from Martinelli's (197I) and Keeler's (1969) measurements. $\sigma_{\mathrm{m}}$ was calculated from Equation (2); that is the characteristic stress was assumed to be given by the maximum strength envelope. Log-log plots of the results are shown in Figures 5 and 6 . It is immediately apparent that there is a functional relationship which justifies the assumptions. Even more important, the data obtained at Berthoud Pass, Colorado, predict the probability of failure of snow at Alta, Utah, to an accuracy of better than \pm 0.05 .

All the data which were noted as "bad run" or "premature break" were assigned zero strength. It is probable that the subjective judgment involved in calling an experiment "bad" accounts for the slight disagreement in the cut-off approximately at $\log R=-\mathrm{I}(R=$ o. $\mathrm{I})$. Martinelli (I97 I) recorded lower strength readings than Keeler (I969). The cut-off indicates that about $10 \%$ of the flaws in the samples were about the same size as the sample diameter $(57 \mathrm{~mm})$ or larger. 


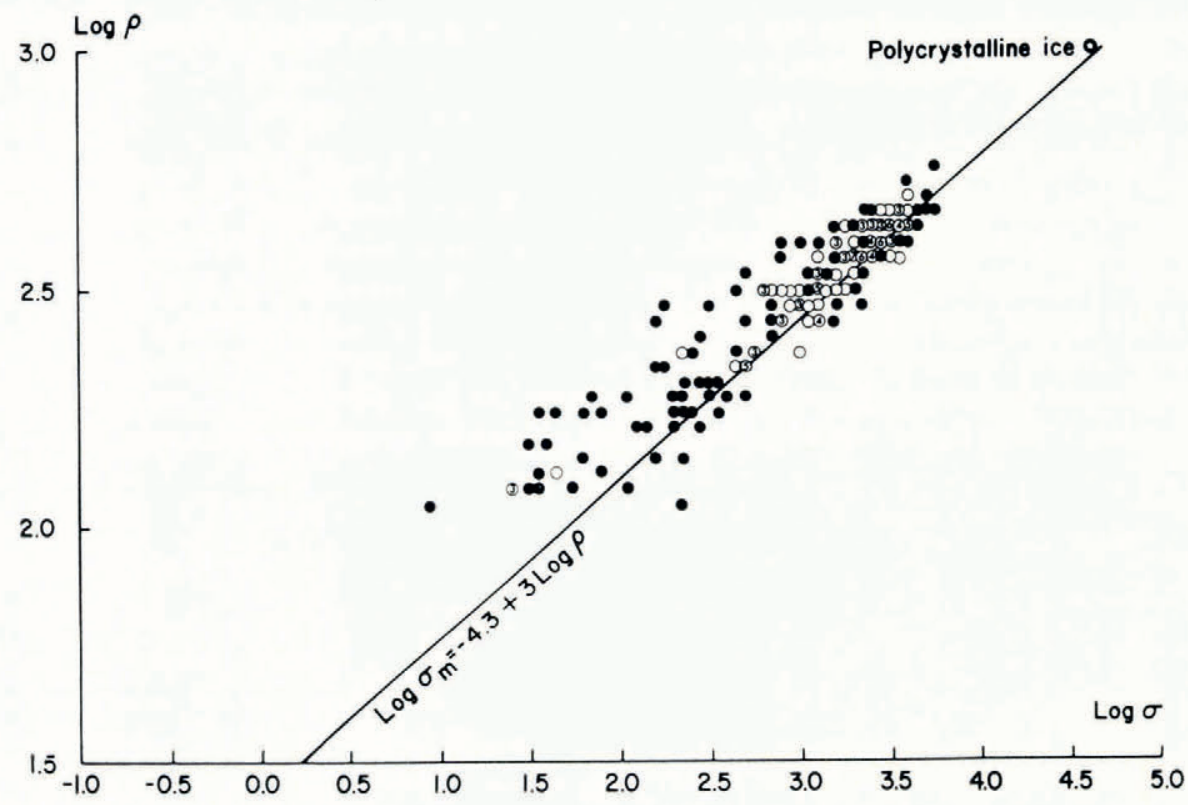

Fig. 4. Similar plot to Figure I using data from Keeler and Weeks (1967).

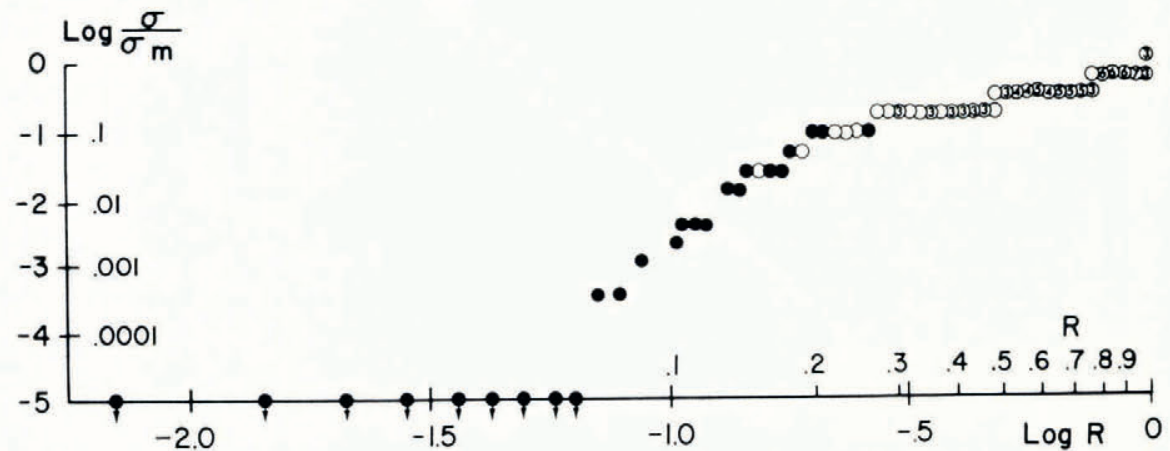

Fig. 5. Logarithm of probability of failure $(\log R)$ versus logarithm of normalized stress $\left(\log \sigma / \sigma_{\mathrm{m}}\right)$ using results from calculations on Martinelli's (1971) data.

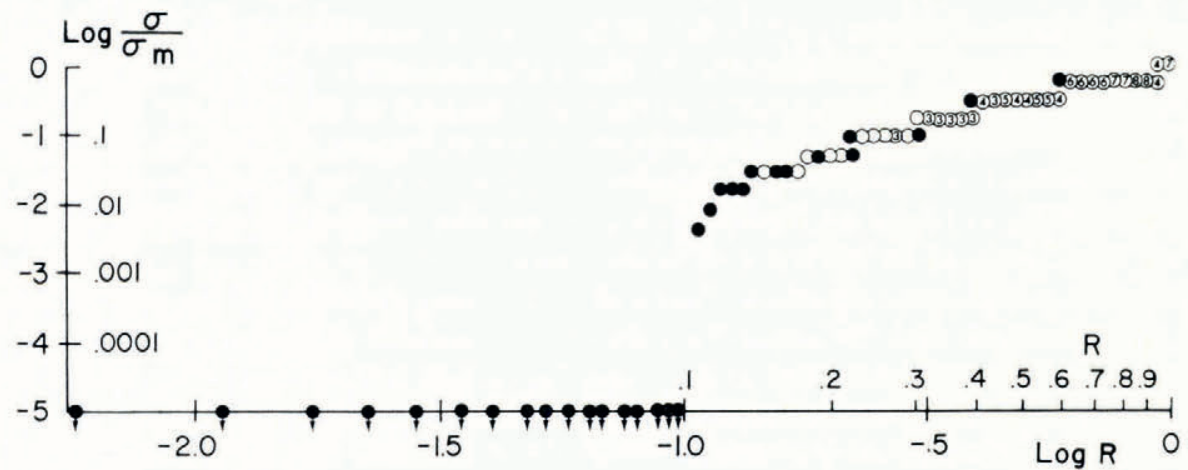

Fig. 6. Similar plot to Figure 5 using results from calculations on Keeler's (1969) data. 
The hypothesis that the maximum strength is a function of density also implies that, at least for similar snow types, there is a particular texture for each density which has the maximum strength. Evidence that such is the case is shown in Figure 7; a three-dimensional plot of density, permeability, and tensile strength for some of Martinelli's (197I) samples. The tensile-strength ridge indicates that for each density there is an optimum permeability. Since permeability and texture are related the conclusion can be drawn that there is an optimum texture for each density.

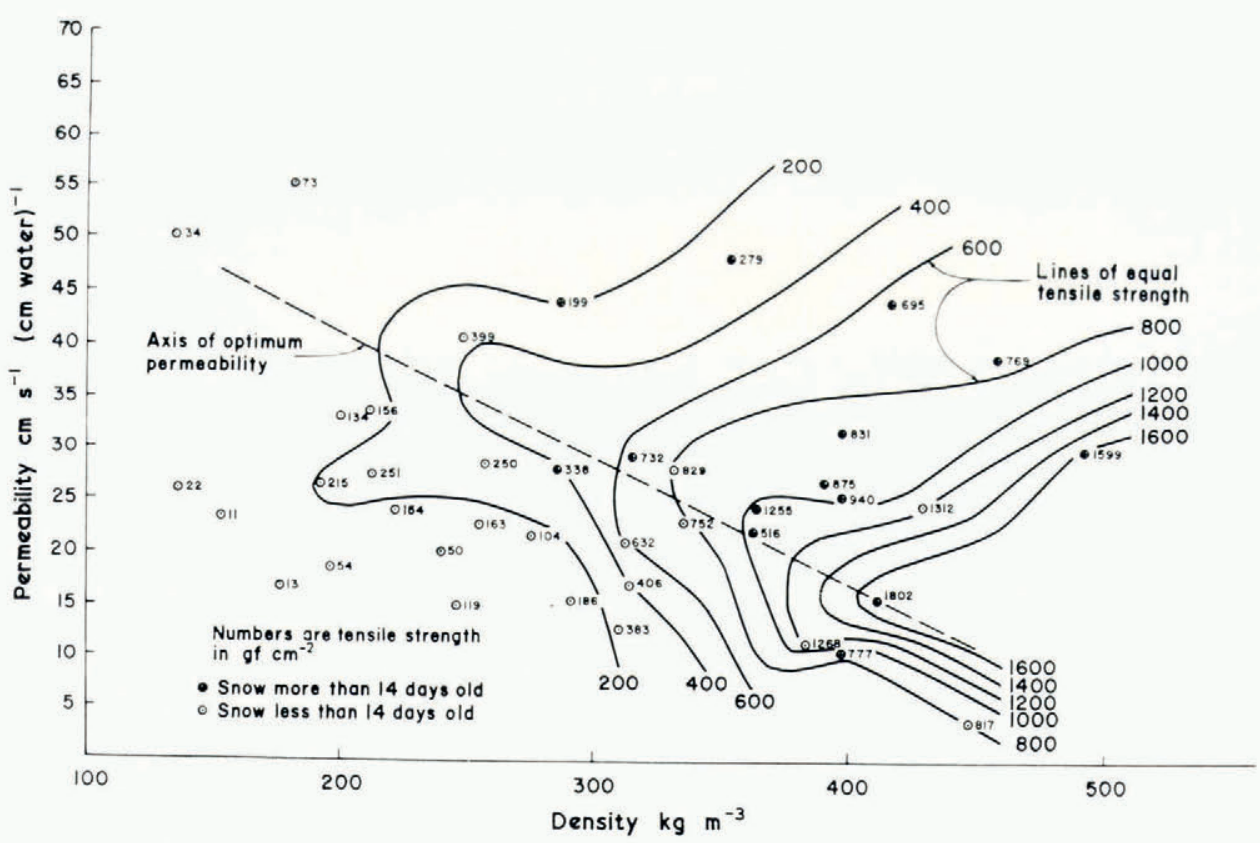

Fig. 7. Tensile strength contours on a plot of density versus permeability (Martinelli, 1971).

The conclusions that can be drawn are:

(I) A maximum strength envelope given by the equation

$$
\log \sigma_{\mathrm{m}}=A+B \log \rho
$$

characterizes centrifugal tensile strength-density measurements. For fairly young snow $A=-4 \cdot 3$ and $B=3$ when $\sigma$ is in units of $\mathrm{I}^{2} \mathrm{~N} \mathrm{~m}^{-2}$ and $\rho$ is $\mathrm{kg} \mathrm{m}^{-3}$.

(2) The probability of failure is a function of the applied stress normalized for the density of the sample.

It should be noted that the constants in Equation (2) are the same for snows which are as different as those found at Berthoud Pass, Colorado, and Alta, Utah. Furthermore there is no apparent temperature dependence at least over the range at which the measurements were performed $\left(c\right.$. $-\mathrm{I}^{\circ} \mathrm{C}$ to $\left.-\mathrm{I}^{\circ} \mathrm{C}\right)$.

These results show that "weakest link" theories of brittle fracture can be applied to snow. In order to develop usable failure criteria for snow in avalanche tracks, it is necessary to extend this work by determining the dependence of strength on the sample volume. Since the larger the sample the more likely it is that a large flaw will be included, the strength will 
depend on the tested volume and the flaw size distribution. It will also be necessary to determine the dependence of strength on metamorphic grade. This can be accomplished by accurately classifying the metamorphic grade of each tested sample.

\section{ACKNowledgement}

The idea for this work grew out of a stimulating discussion with Mr R. Perla.

MS. received 4 Fanuary 1971

\section{REFERENCES}

Bader, H., and others. 1939. Der Schnee und seine Metamorphose, von H. Bader, R. Haefeli, E. Bucher, J. Neher, O. Eckel, C. Thams, P. Niggli. Beiträge zur Geologie der Schweiz. Geotechnische Serie. Hydrologie, Lief. 3. [English translation: U.S. Snow, Ice and Permafrost Research Establishment. Translation 14, 1954.

Bucher, E. 1948. Beitrag zu den theoretischen Grundlagen des Lawinenverbaus. Beiträge zur Geologie der Schweiz. Geotechnische Serie. Hydrologie, Lief. 6. [English translation: U.S. Snow, Ice and Permafrost Research Establishment. Translation 18 , 1956.]

Butkovich, T. R. 1956. Strength studies of high density snow. U.S. Snow, Ice and Permafrost Research Establishment. Research Report 18.

Butkovich, T. R. 1959. On the mechanical properties of sea ice. U.S. Snow, Ice and Permafrost Research Establishment. Research Report 54.

Frenkel, Ya. I., and Kontorova, T. A. 1943. A statistical theory of the brittle strength of real crystals. Journal of Physics (Moscow), Vol. 7, No. 3, p. 108-14.

Griffith, A. A. 1920. The phenomena of rupture and flow in solids. Philosophical Transactions of the Royal Society, Ser. A. Vol. 221 , Art. No. 6, p. 163-98.

Keeler, C. M. 1969. Some physical properties of alpine snow. U.S. Cold Regions Research and Engineering Laboratory. Research Report 271.

Keeler, C. M., and Weeks, W. F. 1967. Some mechanical properties of alpine snow, Montana 1964-66. U.S. Cold Regions Research and Engineering Laboratory. Research Report 227.

Martinelli, M., jr. 1971. Physical properties of alpine snow as related to weather and avalanche conditions. U.S. Forest Service. Research Paper RM-64.

Ramseier, R. O. ${ }^{1963}$. Some physical and mechanical properties of processed snow. Journal of Glaciology, Vol. 4, No. 36, p. 753-69.

Roch, A. 1966. Les déclenchements d'avalanches. Union de Géodésie et Géophysique Internationale. Association Internationale d'Hydrologie Scientifique. Commission pour la Neige et la Glace. Division Neige Saisonnière et Avalanches. Symposium international sur les aspects scientifiques des avalanches de neige, 5-10 avril 1965, Davos, Suisse, p. 182-95.

Weibull, W. 1939. A statistical theory of the strength of materials. Ingeniörsvetenskapsakademiens Handlingar, Nr. ${ }^{1} 5^{1}$. 